\title{
The Tilt Model Acoustic Survey of Intonation in Children with Severe
} Autism

\author{
Zahra Azizi ${ }^{1}$, Shahla Sharifi ${ }^{2} \&$ Mandana Nourbakhsh ${ }^{3}$ \\ ${ }^{1}$ M.A. in Linguistics, Ferdowsi University of Mashhad, Mashhad, Iran \\ ${ }^{2}$ Associate Professor of Linguistics, Ferdowsi University of Mashhad, Mashhad, Iran \\ ${ }^{3}$ Assistant Professor of Linguistics, Alzahra University, Tehran, Iran \\ Correspondence: Shahla Sharifi, Associate Professor of linguistics, Ferdowsi University of Mashhad, Mashhad, \\ Iran. E-mail: sh-sharifi@um.ac.ir
}

Received: May 23, 2016 Accepted: June 12, 2016 Online Published: July 13, 2016

doi:10.5539/ijel.v6n4p78 URL: http://dx.doi.org/10.5539/ijel.v6n4p78

\begin{abstract}
The purpose of this study is an acoustic survey of intonation in a set of declarative and interrogative sentences as uttered by 15 children with severe autism (SA) in comparison with 15 Typically Developing (TD) children. The results indicate that monotony is not a common feature in the speech pattern of all autistic children. More specifically, the results demonstrate that the monotony attributed to the autistic children's production of speech cannot be attributable to all kinds of sentences they produce as they can produce statements and questions fairly similar to typically developing children.
\end{abstract}

Keywords: severe autism, monotone intonation, intonation pattern, duration, tilt, amplitude

\section{Introduction}

Autism is a complex, multi-faceted disorder that affects the neurodevelopment of human beings during their early stages of life and for many lingers throughout adulthood. Autism's inherent features, to name but a few, are difficulties or deficits in communication, social interaction and cognition, and person-to-person behavioral coordination and recall. Autism impacts the affected individual, his/her family, and in some cases the localized community. One of the abnormal features of autism is the deficit in nonverbal communicative behaviors, manifested by absent, reduced, or atypical use of eye contact (relative to cultural norms), gestures, facial expressions, body or speech intonation (American Psychiatric Association, 2013, p. 12). The research of scientists such as Kenner (1943), Bogdashina (2005) and Gallo (2010) shows that there is an abnormality in the prosody of autistic children. They have a monotone intonation and they cannot change intonation when they want to ask a question or produce a statement. Moreover, they cannot distinguish between the intonation of different sentences and are often unable to 'interpret' the speaker's intentions that are expressed through his/her intonation pattern change, often contradicting the literal meaning of the utterance. Therefore, in this research we had two aims for investigating intonation in autistic children: to find out whether autistic children produce intonation in statements and questions with a monotone intonation; and to find out whether the monotone intonation is a common feature among all autistic children.

\subsection{Pervious Research}

Prosody appears to be an important variable from the perspective of child language acquisition (Baltex \& Simmons, 1985). A skill such as prosody that unobtrusively conveys emotional and pragmatic aspects of speech may be particularly vulnerable in children with autism, but those who do not have learning difficulties may be capable of increasing their prosodic awareness and ability. This in turn may enhance their understanding of the subtler aspects of communication, such as the conveying of emotions, attitudes, and social cues (Peppé et al., 2007).

Communicative impairment is one of the features of autism. It can range from total lack of expressive language to reasonably fluent speech with abnormalities in pitch, intonation, rate, rhythm, or stress (Willemsen-Swinkels, 2002). There have been many different findings in the study of intonation in autistic children. For example, Shriberg et al. (2001), in their research on adolescents and adults with High Functioning Autism (HFA) and Asperger Syndrome within the age range of 10-50, show that the prosodic deficits so frequently attributed to 
people with autistic syndromes reside primarily in the pragmatic and affective aspects of prosody with grammatical aspects relatively spared.

Diehl et al. (2008) examined the fundamental frequency variation of 21 children and adolescents with HFA between the ages of 10 and 18 years. These studies provide evidence for differences in expressive prosody in individuals with HFA that can be measured objectively. They found evidence of acoustic measurements of prosody being related to clinical judgments of autism-specific communication impairments.

Nakai et al. (2013) conducted experimental tasks based on the word test proposed by the Japan Clinical Articulation Society. They found out that the TD group exhibited a significantly greater pitch than the ASD group at school age. A significant correlation was observed between the pitch of each word and social reciprocal interaction. Monotonous speech in school-aged children with ASD was detected. The extent of monotonous speech was related to the extent of social reciprocal interaction in children with ASD.

McCann \& Peppē (2003) believe that individuals with autism spectrum disorder speak with an unusual or odd-sounding prosody. Filipe et al. (2014) also believe that individuals with Asperger Syndrome (AS) may show prosodic impairments. They explored the sentence-type difference between statements and questions that is conveyed by intonation, using perceptual and acoustic measurements. Although children with AS could produce categorically accurate prosodic patterns, their prosodic contours were perceived as odd by adult listeners, and acoustic measurements showed alterations in duration and pitch. Additionally, children with AS had a greater variability in fundamental frequency contours compared to typically developing peers.

McCann et al. (2005) and Peppé et al. (2007a, 2011b) state that abnormality in expressive prosody is a widely reported characteristic of the speech of individuals with autism. Hubbard \& Trauner (2006) examined emotional intonation (happy, sad, and angry intonation) in children with autism and compared them with children with Asperger Syndrom and typical development. Their findings show that speakers with autistic spectrum disorders had a larger pitch range than the other groups. Other measures of intonation including amplitude, duration, and location of pitch peak revealed defects that are more complex than predicted. Nadig \& Shaw (2011) found out that the children with HFA have a significantly larger pitch range during both conversation and structured communication.

Simmons \& Baitaxe (1975) mention that autistic children don't have the ability to ask questions in the form of a typical question. Another commonly cited feature is that all autistic individuals have monotony and an abnormal intonation. However, no study states that this abnormality in intonation can hold true for all kinds of the sentences. As we showed above, most of the studies on prosody and intonation in ASD have only focused on high functioning autism and Asperger Syndrome.

In other words, the intonation of questions and statements in children with severe autism has not been studied so far. Similarly, only few acoustic features of intonation have been considered in a handful of surveys. Therefore, in this paper we want to concentrate on those acoustic features of intonation in autistic children that have never been investigated before.

The aim of this study is to conduct an acoustic survey of the intonation of statements and questions in children with severe autism (SA); and to show whether these children are able or unable to produce questions and statements; and if they can produce these two kinds of sentences, there is any abnormality in the production of falling and rising intonations. In sum, we want to find out if monotony is a common feature for all children with autism. For this purpose, we have studied other acoustic features of intonation such as amplitude, tilt and duration.

\section{Method}

The first group of participants in this study consisted of 15 Farsi-speaking children with severe autism (SA) or classic autism with 7-10 years of age and the average age of 8.54 who had a normal level of intelligence. This level of intelligence had been checked before they came to school. The diagnosis of autism and the level of intelligence were ascertained by psychiatrists and child psychologists under supervision of State Welfare Organization, and they were recorded in specific "Health Certificates" that were put at my disposal. The children were picked up from a school for autistic children in Mashhad, Iran that had about 70 autistic children in total, all with severe autism and Asperger Syndrome. After we checked the speaking ability of the students, we decided to choose 15 students who had severe autism (in order to prove the severity of autism, Gilliam Autism Rating Scale, Second Edition (GARS-2) was used. The mean of this test was 74.08 and the standard deviation 8.61.Therefore, all the children were sever autism) and were capable of producing at least one sentence and they do not have learning disability. All of the 15 autistic children were born in Mashhad and their parents were also 
from Mashhad.

The second group of subjects included 15 children with the average age of 8.46 who had been recruited from various schools of TD children. This group of children had been checked up before they entered school, and they had shown no mental, neurobiological, language or speech and hearing disorder. These tests subjects had also been born in Mashhad and lived there since. All the 30 subjects were male because there were no female subjects of the same age and with the same features as the SA children available at the respective schools from which they had been picked.

\subsection{Data Collection}

For this stage, we consulted a speech pathologist, and designed a simple pictorial test together. This test consisted of 19 pictures which were chosen from The Pictorial Dictionary of [Persian] Verbs (Sahraei, 2014). Each picture showed an action. The pictures were printed on cards. During the testing day, the subjects were asked to describe the action shown in each picture in statements, and also to ask questions about the action in the picture. For this stage, we consulted with a speech pathologist, and designed a simple pictorial test together. This test consisted of 19 pictures which were chosen from The Pictorial Dictionary of [Persian] Verbs (Sahraei, 2014). Each picture showed an action. The pictures were printed on cards. During the testing day, the subjects were asked to describe the action shown in each picture in statements, and also to ask questions about the action in the picture. Every subject produced 10 complete statements and 10 questions. In addition to these sentences, the specific conditions of the environment caused the autistic children to ask unconsciously a number of questions about the pictures. The voices of the two groups were recorded with a Sony Recorder ICD-UX523F in the acoustic laboratory of Mashhad's Ferdowsi University under the same conditions. Therefore, there was no background noise involved. The Pra at program 5.4.08 was used to analyze the 600 recorded sentences and those unconscious sentences that are produced by autistic children.

\subsection{Data Analysis}

Data analysis was conducted by employing two models. In order to obtain the duration, amplitude, and tilt, first a model named the "Rise/Fall/Connection Model (RFC)" (Taylor, 1995), and then the Tilt Intonation Model (Taylor, 1998) were used.

The aim of the first model is to provide a complete mapping between acoustics and phonology. In this model, the rises, falls and connections are termed "elements". Rise element (r) is used to represent the rising parts of $F_{0}$ contours. Fall element (f) is used to represent the falling parts of $F_{0}$ contours. Connection elements (c) are straight lines of any gradient or duration and they are used everywhere else; specifically to model parts of contour which do not have a pitch accent or a phrase boundary rise. Therefore, the peak accent is called a "rise element" which is followed by a "fall element". The amplitude and duration scaling factors are called "element parameters" (Taylor, 1995).

On the other hand, the Tilt Intonation Model is designed to facilitate automatic intonational processing for speech technology applications. The model represents intonation at a phonetic level as a sequence of parameterized intonational events (Taylor, 1998).

At first the pitch range $(\mathrm{Hz})$ was changed from 75-300 to 200-500 that is the normal pitch range for children. After the $\mathrm{F}_{0}$ contours had been drawn, and the $\mathrm{r}, \mathrm{f}$, and $\mathrm{c}$ points were marked on it, the maximum and minimum amount of each point were computed. Figure 1 shows how the pitch counter of a declarative sentence was divided to $r$, $f$ and $c$ elements. 


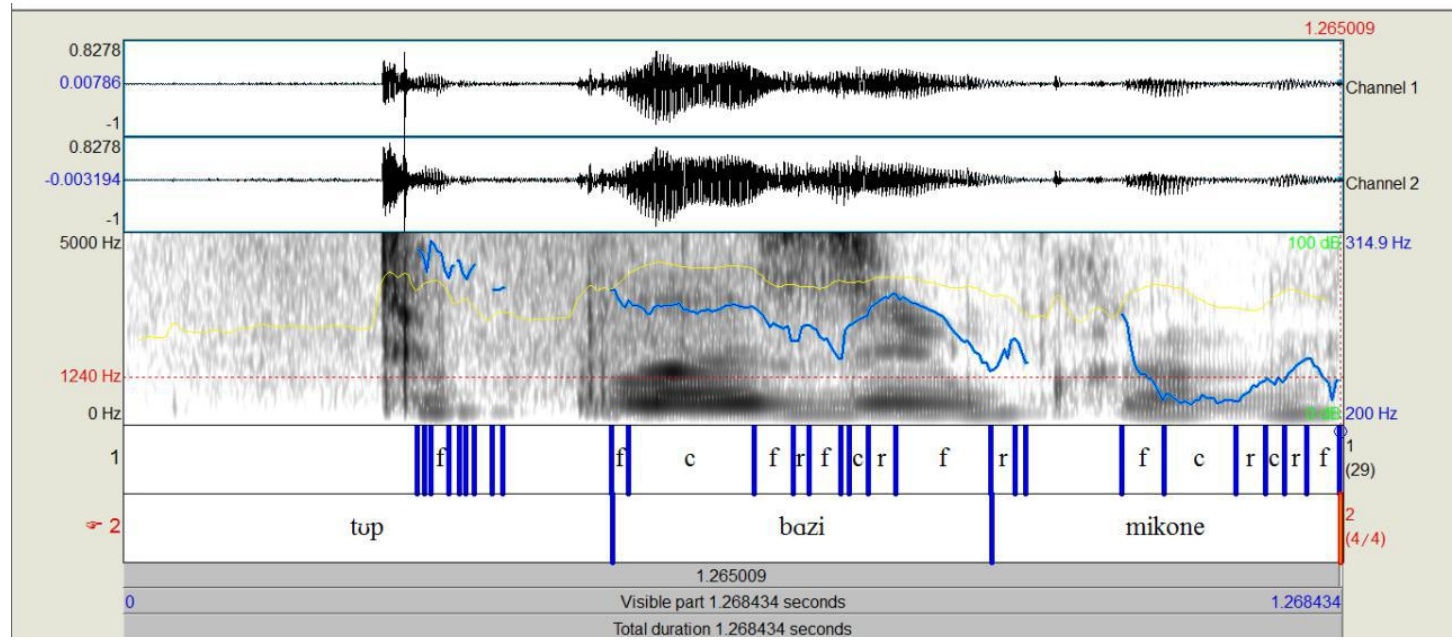

Figure 1. The pitch counter of an declarative sentence which was divided to $r, f$ and $c$ elements

A rise amplitude (A rise) and a fall amplitude (A fall) were calculated through the following formulas:

$$
\begin{aligned}
& A_{\text {rise }}=\max _{\text {rise }}-\min _{\text {rise }} \\
& A_{\text {fall }}=\max _{\text {fall }}-\min _{\text {fall }}
\end{aligned}
$$

Amplitude was calculated via the following formula:

$$
A_{\text {event }}=A=\left|A_{\text {rise }}\right|+\left|A_{\text {fall }}\right|
$$

For calculating duration, first the duration of each part of event (rise and fall) were calculated by using the Praat duration script, and then the whole duration was computed through the following formula:

$$
D_{\text {event }}=\left|D_{\text {rise }}\right|+\left|D_{\text {fall }}\right|
$$

Tilt is a dimensionless parameter, only describing the shape of the event. Tilt is calculated from the relative sizes of the rise and fall components in the event. Each event has a rise and fall component that can vary in size. Some events have a zero rise or zero fall component, indicating that they only have a fall or a rise, respectively, where the "middle" of the event is defined as the end of the rise component or start of the fall component. Each event is characterized by the tilt parameters, which fully describe its $\mathrm{f}_{0}$ shape with a number of linguistically useful variables (Taylor, 1998). In order to calculate tilt, at first the tilt amplitude and duration were computed according to formulas (5) and (6).

$$
\begin{aligned}
& \text { tiltamp }=\frac{\mid \text { Arise }|-| \text { Afall } \mid}{\mid \text { Arise }|+| \text { Afall } \mid} \\
& \text { tiltdur }=\frac{\mid \text { drise }|-| \text { dfall } \mid}{\mid \text { drise }|+| \text { dfall } \mid}
\end{aligned}
$$

Finally, the tilt of each event was calculated via formula (7):

$$
\text { tilt }=\frac{\text { tilt }_{a m p}+\text { tilt }_{d u r}}{2}
$$

\subsection{Statistical Method}

In order to compare the duration, amplitude and tilt between the SA and TD children, first the normality of variable was proved through a statistical test, namely, Kolmogorov-Smirnov Test. Because the data did not deviate from normality, a parametric test, namely, Independent T-Test, was used to compare the duration, amplitude and tilt. The Chi Square Test was also used to test the falling-rising intonation in these two groups.

\section{Result}

An alpha level 0.05 was used for all statistical tests. When variables passed the normality test, an Independent Samples T-Test was used to compare the duration, amplitude and tilt. The results are shown in Tables 1, 2 and 3. 
In these tables we used $\mathrm{s}$ and $\mathrm{q}$ after duration, amplitude and tilt $\mathrm{s}$ and $\mathrm{q}$ being abbreviations for statements and questions. The number $(\mathrm{N})$ of the autistic children who could produce the questions was 14 . Only one could not produce the questions. SD is an abbreviation for Standard Deviation of the variable.

\subsection{Duration}

The result in Table 1 shows that the $p$ value in statements is more than $(0.05)$. In the second part of the hypothesis, as it is shown in Table 1 , the $p$ value is equal to 0.218 , which is more than 0.05 . It means that there is no significant difference in the duration of the declarative and the interrogative sentences between SA and TD.

Table 1. Result of analysis for duration in declarative and interrogative sentences

\begin{tabular}{lllllll}
\hline Duration & Group & SD & N & Mean & Sig & Sig (2-tailed) \\
\hline \multirow{2}{*}{ Duration $s$} & SA & 0.04712 & 15 & 0.1578 & \multirow{2}{*}{0.413} & 0.954 \\
& TD & 0.03649 & 15 & 0.1569 & & \multirow{2}{*}{0.218} \\
\hline \multirow{2}{*}{ Duration $q$} & SA & 0.04139 & 14 & 0.1913 & 0.254 & 0.2135 \\
\end{tabular}

\subsection{Tilt}

As the normality of the variable was proved, the parametric test, Independent T-Test, was used. As it is shown in Table 2, the $\mathrm{p}$ value of statements is more than (0.05). In the second part of the hypothesis, the same result was obtained for interrogative sentences. The $\mathrm{p}$ value was more than (0.05). As a result, the tilt in declarative and interrogative sentences was not significantly different from SA to TD.

Table 2. Result of analysis for tilt in declarative and interrogative sentences

\begin{tabular}{lllllll}
\hline Tilt & Group & SD & N & Mean & Sig & Sig (2-tailed) \\
\hline \multirow{2}{*}{ Tilt $s$} & SA & 0.08557 & 15 & 0.151 & \multirow{2}{*}{0.127} & 0.063 \\
& TD & 0.11085 & 15 & 0.551 & & \multirow{2}{*}{0.349} \\
\hline
\end{tabular}

\subsection{Amplitude}

As it is shown in Table 3, the p value of statements is more than (0.05). In the second part of the hypothesis, the $\mathrm{p}$ value of the questions is more than (0.05). Therefore, the amplitude in SA and TD is the same.

Table 3. Result of analysis for amplitude in declarative and interrogative sentences

\begin{tabular}{lllllll}
\hline Amplitude & Group & SD & N & Mean & sig & Sig (2-tailed) \\
\hline \multirow{2}{*}{ Amplitude $s$} & SA & 19.54 & 15 & 66.6387 & \multirow{2}{*}{0.340} & \multirow{2}{*}{0.140} \\
& TD & 15.34 & 15 & 56.8658 & & \multirow{2}{*}{0.124} \\
\multirow{2}{*}{ Amplitude q } & SA & 30.42 & 14 & 79.0759 & 0.029 & \multirow{2}{*}{ TD } \\
& TD & 15.59 & 15 & 64.4687 & & \\
\hline
\end{tabular}

\subsection{Intonation Pattern}

The statistical test, Chi Square Test, was also used to compare the falling-rising intonation between SA and TD. The $\mathrm{p}$ value in statements is equal to $(0.043)$, and it is less than $(\alpha=0.05)$. In the second part of the hypothesis, the $\mathrm{p}$ value is equal to $(0.00)$, and it is less than $(\alpha=0.05)$. Therefore, there is a significant difference in the falling-rising intonation between SA and TD. 


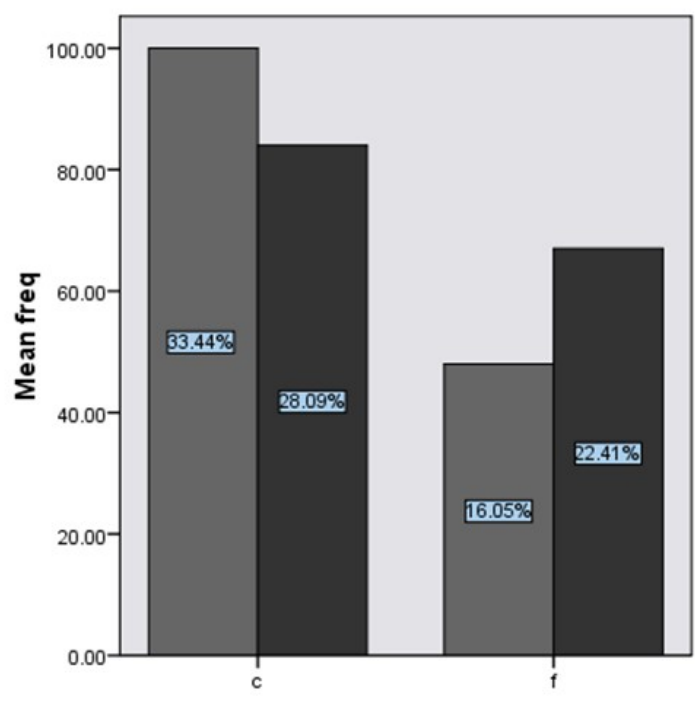

口ASD

Figure 2. The percent frequency falling and connection of declarative sentences in SA and TD

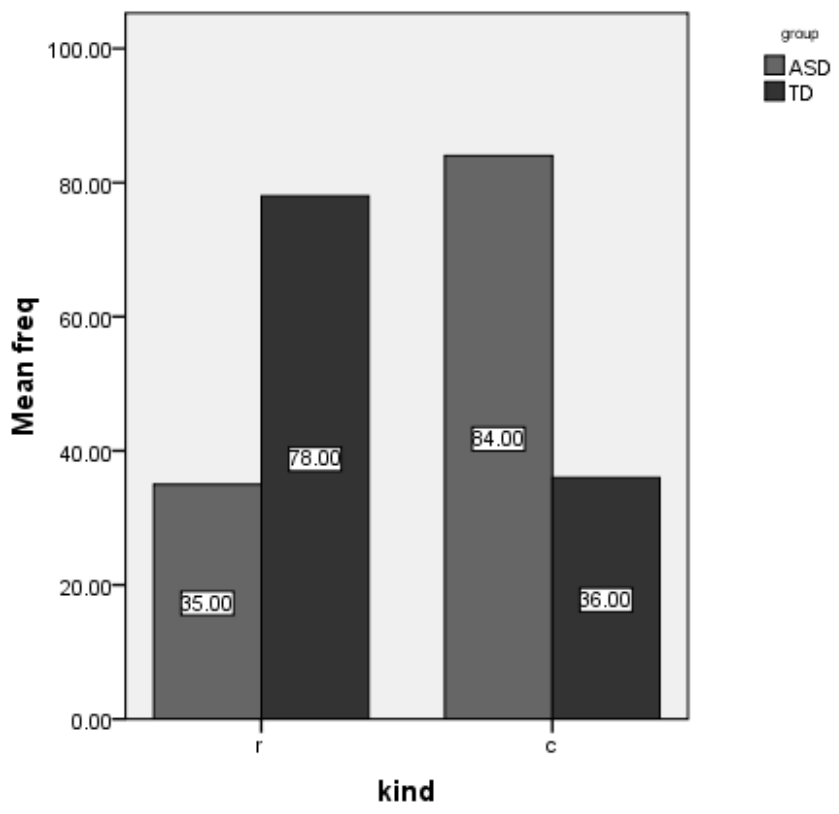

Figure 3. The percent frequency rising and $\mathrm{c}$ onnection of interrogative sentences in SA and TD

\section{Discussion}

The aim of this study was to conduct an acoustic survey of the intonation of statements and questions in children with autism, and to show whether these children are unable to produce questions and statements or not. Another aim was to assess the abnormality in their production of falling and rising intonations, if there was any. Yet another aim was to investigate whether autistic children demonstrate monotony in their production of statements and questions or not. The final aim of our study was to investigate a number of acoustic feature of the autistic children's intonation such as duration, amplitude and tilt to find out whether there is any abnormality in them or not. In order to do this research, 30 subjects with 7-10 years of age were chosen; 15 children with autism and 15 typically developing children. The pattern of intonation is typically different between autistic children and TD.

In order to investigate the acoustic element of intonation (amplitude, duration, tilt) accurately, the RFC model of 
intonation and the Tilt Model of Intonation, which provided a complete mapping between acoustics and phonology and an exact acoustic analysis, were used. In the first statistic hypothesis, the durations of statements and questions were surveyed, and the result in Table 1 indicated that there is no significant difference in the two kinds of sentences between the two groups. In the second hypothesis, the result of which was shown in Table 2, there is not a significant difference between the tilt of the declarative and the interrogative sentences in children with autism and TD. The results in the Table 3 indicate that the amplitude of the declarative and the interrogative sentences are not significantly different between the children with autism and the typically developing children.

In this research we focused only on children with severe autism. Our findings, in accordance with Azizi (2015), showed that there was no abnormality in the acoustic features such as duration, tilt and amplitude between the SA and the TD in statements and questions. In the first acoustic analysis, our results showed that there were maximum and minimum pitches in the production of statements and questions by the SA; and that those maximum and minimum amounts were the same as our TD results. We demonstrated that amplitude and tilt were also the same in both group, which means there is no defect in the intonation of statements and questions produced by autistic children. This also shows that as there is no difference in duration, autistic children have no difficulty in measuring the timing of word production, and so they can produce the word in the same duration as the TD children do.

Therefore, the variety in pitch and lack of any significant difference in tilt and amplitude mean that the children with autism are not monotonous in intonation while producing statements and questions. This is while previous studies had indicated abnormalities in the acoustic features of the expressive prosodies of HFA and SA; and had therefore concluded that children with autism were monotonous in their intonation. On the contrary, we proved that autistic children can learn and produce the intonation pattern of their language the same as the TD children do if they don't have any IQ and learning problems. Moreover, it can be concluded that it is because the Persian language is an international language whose speakers can change the intonation pattern of their sentences without any syntactic change that it is easy for autistic children to learn or even imitate the intonation pattern of statements and questions.

The last hypothesis examined whether there was a falling or rising intonation in the production of declarative and interrogative sentences or not. After analyzing the declarative sentences, the results showed that there was a difference between the production of declarative sentences in the SA and the TD. The Percent Frequency (PF) c in the SA was $54.3 \%$ while it was $45.7 \%$ in the TD. The (PF) $\mathrm{f}$ in the SA was equal to $41.7 \%$ and in the TD to $58.3 \%$. The second part of the hypothesis showed that the production of interrogative sentences between SA and TD were different. The (PF) $\mathrm{c}$ in the SA was equal to $70 \%$ while $(\mathrm{PF}) \mathrm{c}$ in the TD was $30 \%$. The (PF) $\mathrm{r}$ in SA was $31 \%$ and in the TD $71 \%$. This hypothesis shows that although autistic children can produce questions and statements with the appropriate intonation, some of them have difficulty in producing right intonations especially regarding questions. However, this does not mean that they are monotone, because they can unconsciously produce questions. For example, when they became curious about an action in the pictures, they asked questions about them with a rising intonation. This happened many times during the test and these questions were recorded and analyzed. The analysis showed that the acoustic features of those questions were the same as the acoustic features of TD children. However, the problem with autistic children was that they produced the questions with a falling intonation when asked to consciously produce questions. This means they don't know what the meaning of a question is.

Simmons \& Baitaxe (1975) had argued that autistic children are not able to ask questions in the manner of typical questions. However, as was shown above, our study proved that this is not necessarily the case. As a matter of fact, most autistic children are able to properly produce both questions and statements. Interestingly, we realized that those who were not able to produce questions with a rising intonation could unconsciously produce them. Indeed, the main reason those children were not able to produce questions with a rising intonation was due to their lack of understanding of the concept of question. In our study, we proved that children with severe autism do not demonstrate monotony in their production of statements and questions. We also showed that not all children with autism have a monotonous intonation. In this study, we reached the same conclusion as Hubbard \& Trauner (2006) had when examining emotional intonation (happy, sad, and angry) in children with autism; i.e., there is no monotony in autistic children's happy, sad, and angry intonations. As result, in order to improve the speaking abilities of autistic children, the pathologists should not only focus on the "production" of intonation in statements and questions by autistic children but also on their "cognition," i.e., the autistic children's understanding of the meaning of these two kinds of sentences. That is because if the children can learn the meaning of the statement and the question, they can use and produce them as TD children do.

For future research, we suggest studies to be conducted on other types of sentences such as imperative and 
exclamatory in order to indicate whether children with autism produce these types of sentences with a monotone intonation or not.

\section{Conclusion}

In this research we have conducted an acoustic study of intonation on autistic children. As the focus of previous studies in our line of study had been the production of prosody and intonation in children with High Functioning Autism (HFA) and Asperger Syndrome (AS), we chose to concentrate on children with severe autism instead. Although previous studies had stated that the communication disorder in SA is less severe than in AS and HFA, our findings showed that it was not necessarily the case. We showed in our research that monotony is not a common feature in all children with autism. We also made it clear that the monotony attributed to the autistic children's production of speech cannot be attributable to all kinds of sentences they produce as we showed that they can produce statements and questions fairly similar to typically developing children.

\section{Acknowledgements}

We wish to acknowledge our gratitude to the directors of the schools for autistic children, Miss Elahm Mosapour and Mr. Salehi, who collaborated with us to pick from among their students our study subjects. We are also grateful to the families of the ASD subjects who let their children participate in this study. In addition, we would like to thank Dr. Davod Sobhani, the speech pathologist who assisted us in designing the test; and Ms. Marzieh Alizadeh, the autism specialist in the State Welfare Organization. Our special thanks go to Mr. Reza Parchizadeh for editing and proofreading the article. It is to be mentioned that for this survey we received no funding whatsoever from any individual, university or organization, and that we completely funded this survey ourselves.

\section{References}

Azizi, Z. (2015). The acoustic survey of intonation in Autism Spectrum Disorder. The Journal of Acoustic Society of America, 137, 2207. http://dx.doi.org/10.1121/1.4920033

Baltax, A. M., \& Simmon, J. Q. (1985). Prosodic development in normal and autistic children. Communication Problems in Autism, 44, 95-125. http://dx.doi.org/10.1007/978-1-4757-4806-2_7

Boersma, P., \& Weenink, D. (2015). Praat: Doing Phonetics by Computer (Version 5.4.08) [Praat]. Retrieved from http://www.fon.hum.uva.nl/praat/

Bogdashina, O. (2005). Communication issues, in autism and asperger syndrome. London: Jessica Kingsley Publishers.

Brisson, J., Martel, K., Serres, J., Sirois, S., \& Adrien, J. L. (2014). Acoustic analysis of oral productions of infants later diagnosed with autism and their mother. Infant Mental Health Journal, 35(3), 285-295. http://dx.doi.org/10.1002/imhj.21442

Diagnostic and statistical manual of mental disorders: DSM-5 (5th ed.). (2013). Washington, DC, London: American Psychiatric Publishing.

Diehl, J. J., \& Paul, R. (2011). Acoustic differences in the imitation of prosodic pattern in children with with autism spectrum disorder. Research in Autism Spectrum Disorder, 6, 123-124. http://dx.doi.org/10.1016/j.rasd.2011.03.012

Diehl, J. J., \& Watson, D. (2008). An acoustic analysis of prosody in high-functioning autism. Applied Psycholinguistics, 30, 385-404. http://dx.doi.org/10.1017/S0142716409090201

Filipe, M. G., Frota, S., Castro, S. L., \& Vicente, S. G. (2014). Atypical prosody in asperger syndrome: Perceptual and acoustic measurements. J Autism Dev Disord. http://dx.doi.org/10.1007/s10803-014-2073-2

Gallo, D. P. (2010). Diagnosing autism spectrum disorders. UK: Blackwell Publishing.

Hubbard, K., \& Trauner, D. A. (2007). Intonation and emotion in autistic spectrum disorders. J Psycholinguist Res, 36, 159-173. http://dx.doi.org/10.1007/s10936-006-9037-4

Kanner, L. (1943). Autistic disturbances of affective contact. Nervous Child, 2, 217-250.

McCann, J., \& Peppé, S. (2003). Prosody in autism spectrum disorders: a critical review. International Journal of Language \& Communication Disorders, 38, 325-350. http://dx.doi.org/10.1080/1368282031000154204

McCann, J., Peppé, S. E., Gibbon, F., O’Hare, A., \& Rutherford, M. (2007). Prosody and its relationship to language in school-aged children with high-functioning autism. International Journal of Language \& Communication Disorder, 42, 682-702. http://dx.doi.org/10.1080/13682820601170102

Nadig, A., \& Shaw, H. (2011). Acoustic and perceptual measurement of expressive prosody in High-Functioning 
autism: Increased pitch range and what it means to listeners. J Autism DevDisord, 42, 499-511. http://dx.doi.org/10.1007/s10803-011-1264-3

Nakai, Y., Takashima, R., Takiguchi, T., \& Takada, S. (2013). Speech intonation in children with autism spectrum disorder. Brain and Development, 36(6), 516-522. http://dx.doi.org/10.1016/j.braindev.2013.07.006

Peppé, S., Cleland, J., Gibbon, F., O’Harre, A., \& Castilla, P. M. (2010). Expressive prosody in children with autism spectrum conditions. Journal of Neurolinguistics, 24, 41-53. http://dx.doi.org/10.1016/j.jneuroling.2010.07.005

Peppé, S., McCann, J., Gibbon, F., O’Hare, A., \& Rutherford, M. (2007). Receptive and expressive prosodic ability in children with high-functioning autism. Journal of Speech, Language, and Hearing Research, 50, 1015-1028.

Sahraei, N. (2014). The pictorial dictionary of [Persian] verbs (7th ed.). Tehran: Amuzesh- No'Amouz.

Shriberg, L. D., Paul, R., McSweeny, J. L., Klin, A., Cohen, D. J., \& Volkmar, F. R. (2001). Speech and prosody characteristics of adolescents and adults with high-functioning autism and asperger syndrome. Journal of Speech, Language, and Hearing Research, 44, 1097-1115.

Simmons, J. Q., \& Baltax, C. (1975). Language patterns of adolescent autistics. Journal of Autism and Childhood Schizophrenia, 5, 333-351. http://dx.doi.org/10.1007/bf01540680

Tanguay, P. (2000). Pervasive developmental disorders: A 10-year review. J Am Acad Child Adolesc Psychiatry, 39(9), 1079-95. http://dx.doi.org/10.1097/00004583-200009000-00007

Taylor, P. (1995). The Rise/Fall/Connection model of intonation. Human Communication Research Centre, 15, $1-23$.

Taylor, P. (1998). The tilt intonation model. Centre for Speech Technology Research, 34, 132-138.

Willemsen-Swinkels, S. H. N., \& Buitelaar, J. K. (2002). The autistic spectrum: subgroups, boundaries, and treatment. Psychiatric Clinics of North America, 25, 811-836. http://dx.doi.org/10.1016/S0193-953X(02)00020-5

\section{Copyrights}

Copyright for this article is retained by the author(s), with first publication rights granted to the journal.

This is an open-access article distributed under the terms and conditions of the Creative Commons Attribution license (http://creativecommons.org/licenses/by/3.0/). 